\title{
МОРФОЛОГИЯ ЦИРКОНА КЕМБРИЙСКИХ ОТЛОЖЕНИЙ СЕВЕРНОЙ ПРИБАЛТИКИ
}

При минералогическом изучении кембрийских отложений Северной Прибалтики наряду с количественным подсчетом нами определялись соотношения типоморфных особенностей отдельных минералов, а также постседиментационные их изменения, как индикаторы восстановления процессов литогенеза рассматриваемых отложений. Соотнонения типоморфных особенностей минералов являются более надежными стратнграфическими и палеогеографическими крітериями, чем количественные содержания самих минералов, тесно зависящие от гранулометрии отложений и фациальной обстановки седиментации. Рассматривался весь кембрийский разрез и нижележащие отложения регрессивной части валдайской серин.

Минералогические исследования в общих чертах подтверждают используемое в настоящее время в Әстонии расчленение кембрия, по которому нижняя часть ломоносовской свиты по унифицированной схеме относится к валдайской серии, верхняя - к лонтоваской свите, а верхи тискреской свиты - к нерасчлененному средне-верхнему кембрию (Мардла, Менс и др., 1968); по данным* К. Менс, Ә. Пиррус и др., лонтоваская свита подразделяется на четыре пачки (снизу вверх): I - румбаская, II - махуская, III - кестлаская и IV - виймсиская. Первая пачка лонтоваской свиты по минералогическому составу подразделяется на две части $\left(\mathrm{I}^{1}\right.$ и $\left.\mathrm{I}^{2}\right)$, а третья и четвертая пачки минералогически различаются незначительно (таблица). Эти стратиграфические выводы обосновываются результатами изучения всех составляющих минералов.

Изученные отложения представлены комплексом глинистых и песчано-алевролитовых пород. Песчано-алевролитовая толща валдайской серии содержит маломощные прослои глин. Лонтоваская свита сложена в основном глинами с гнездами и прослойками алевролита и песчаника. Алевролиты и песчаники нанболее характерны для нижней пачки свиты и образуют в западной части Әстонии слои мощностью до 30 м. Люкатиская свита характеризуется чередованием глин, алевролитов и песчаников. Верхняя часть рассматриваемого кембрийского разреза представлена сравнительно однородной толщей крупнозернистых алевролитов и мелкозернистых песчаников. Глубина залегания кровли рассматриваемых отложений различна, колеблясь от выхода на поверхности на севере до глубины $400 \mu$ на юге.

Среди прозрачных аллотигенных тяжелых минералов в изученных отложениях доминирует циркон, составляющий обычно $30-60 \%$ минералов этой группы. Зерна циркона нередко имеют признаки коррозии. Во многих препаратах ст $1 / 5$ до $1 / 3$ части общего количества зерен цир-

* Вийдинг Х., Менс К., Пиррус Э., Клеесмент А. 1970. Литология и распространение отложений балтийской серии в Северной Прибалтике. Рукопись в фондах Ин-та геол. АН ЭССР. 
кона разъедено. Регенерация циркона менее развита, чем коррозия, но все же на отдельных урсвнях более $10 \%$ зерен этого минерала регенерированы (см. таблицу). Разъедание циркона в осадочных комплексах счнтается большинством исследователей чрезвычайно редким явлением, которое происходит только в условиях больших давлений (Saxena, 1966; Kalsbeek, 1967; Marshall, 1967; Руденко, 1968). Формы разъедания циркона в осадочных породах впервые описаны в 1948 году Р. Стевенсом и Д. Корроном (см. Saxena, 1966). Чаще обнаруживаются зерна циркона, измененные за счет гидротермальных воздействий (Жиров, 1952; Винчелл и Винчелл, 1953). Регенерированные зерна циркона в осадочных комплексах встречаются чаще, но обычно также из больших глубин залегания (Pacham, Crook, 1960; Saxena, 1966; Kalsbeek, 1967; Marshall, 1967).

В изученных нами отложениях преобладают бесцветные изометрические зерна циркона (см. таблину), кристаллическая форма которых представляет собой комбинацию призмы и дипирамиды. Дипирамиды в большинстве случаев имеют тупые вершины (табл. 1, фиг. 1-3). Окра . шенных зерен циркона обычно меньше 20\%. Среди них преобладают коричневые - желтых и розовых разновидностей мало. В литостратиграфическом аспекте заслуживает внимания то обстоятельство, что в валдайской серии, лонтоваской и люкатиской свитах коричневые цирконы в большинстве случаев окрашены слабее, чем в вышележащих отложениях. Количество желтого циркона в пробах сильно колеблется $(0-27 \%)$. Возможно, что желтая окраска циркона во многих случаях является вторичной, обусловленной окислением сульфидов железа. Это снижает стратиграфическую ценность данного признака.

Примерно $1 / 3$ часть зерен циркона содержит включения. Сравнительно мало их в цирконах румбаской пачки лонтоваской свиты (см. таблицу). Включения обычно мелкие и неопределимого состава; только в отдельных случаях можно выделить кварц, рутил, хлорит и пирит.

Цирконы зонального строения в изученных отложениях довольно обычны, особенно в породах валдайской серии и нижней пачки лонтоваской свиты. Зональные зерна циркона характеризуются меньшей окатанностью и большей трещнноватостью. Зональные цирконы изученных отложений, по А. Краснобаеву $(1970)$, счигаются характерными для гранитов и гнейсов (табл. I, фиг. 2, 3). Г. Агафонова (1961) считает подобные зональные цирконы характерными для пегматитов. По К. Хуттону, зональные цирконы образуются от радиоактивного распада элементов в цирконе, а по С. К. Саксена (Saxena, 1966) - в результате роста минерала в отложениях. В изученных отложениях наблюдается корреляция между содержанием зональных, загрязненных и трещиноватых цирконов и содержанием монацита. Особенно четко она выра-

\section{Таблица I}

1 - циркон изометрический, окатанный, $\times 600$; скв. Колка, гл. $907,5-908,0$ м; 2 -циркон изометрический, малоокатанный, зональный, $\times 600 ;$ скв. Колка, гл. 877,0877,5 м; 3 - циркон изометрический, неокатанный, с поперечным каналом разъедания, $\times$ ×00; скв. Арукюла, гл, 189,5-193,0 м; 4 - циркон изометрический, окатанный, : выемкой разъедания, $\times 600$; скв. Вильянди, гл. 434,5 м; 5 - циркон разъеденный, $\times \check{000}$; скв. Арукюла, гл. 211,0-220,6 м; 6 - циркон изометрический, полуокатанный, с углубленнем разъедання, заполненным глауконитом, $\times 600$; скв. Арукюла, гл. 141,3 ж; 7 - циркон изометрическнй, с шестиугольной ямкой разъедания, $\times 500 ;$ скв. Кунда, гл. $72,45-72,55$ м; 8 - циркон удлиненный, разъеденный, $\times 600$; скв. Колка, гл. 904,0-904,4 м; 9 - циркон сильно разъеденный, неправильной формы, $\times 600 ;$ скв. Колка, гл. $877,0-877,5 м ; 10$ - циркон сильно разъеденный, неправильной формы, Х600; скв. Колка, гл. $853,5-856,0$ м. 


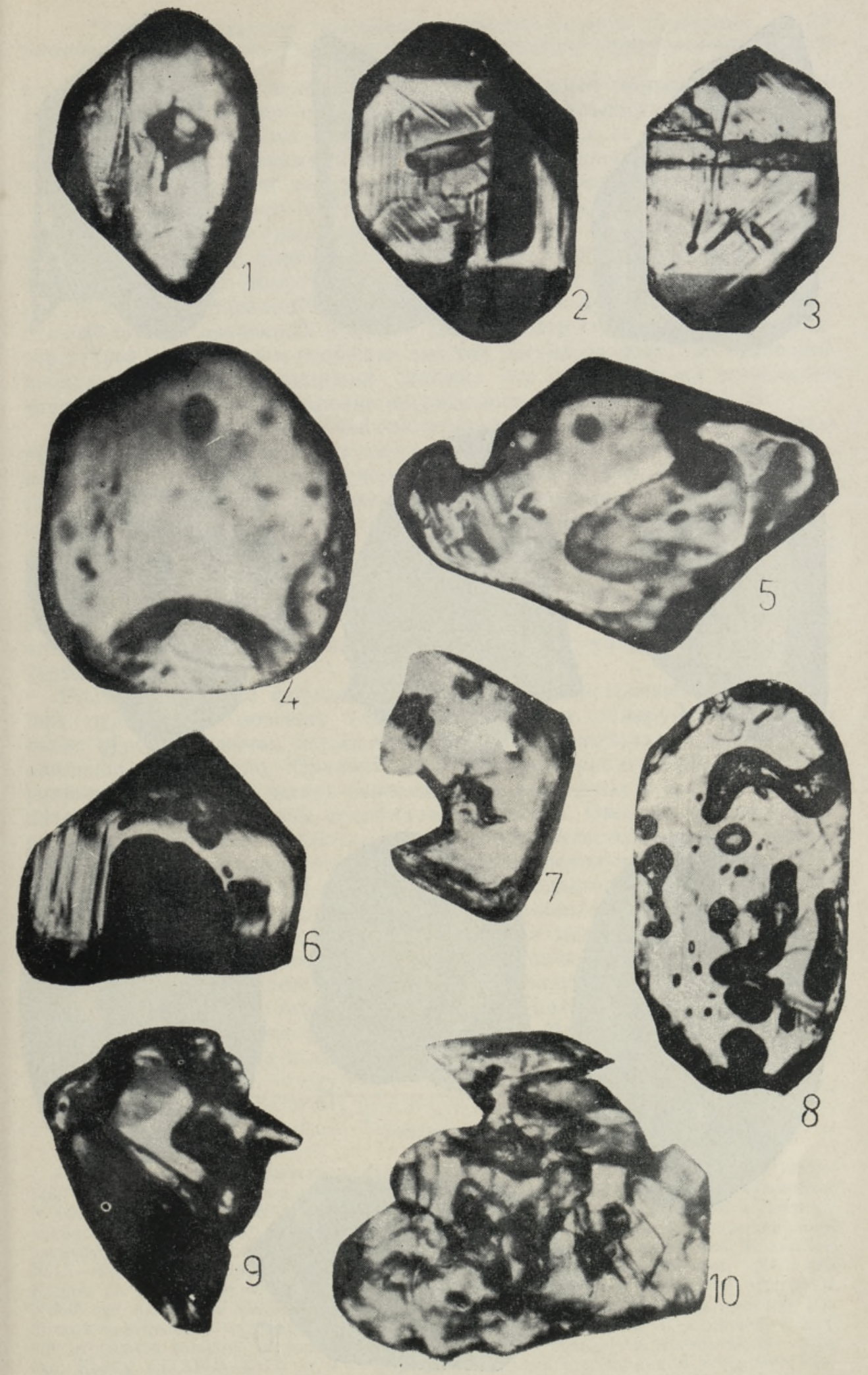




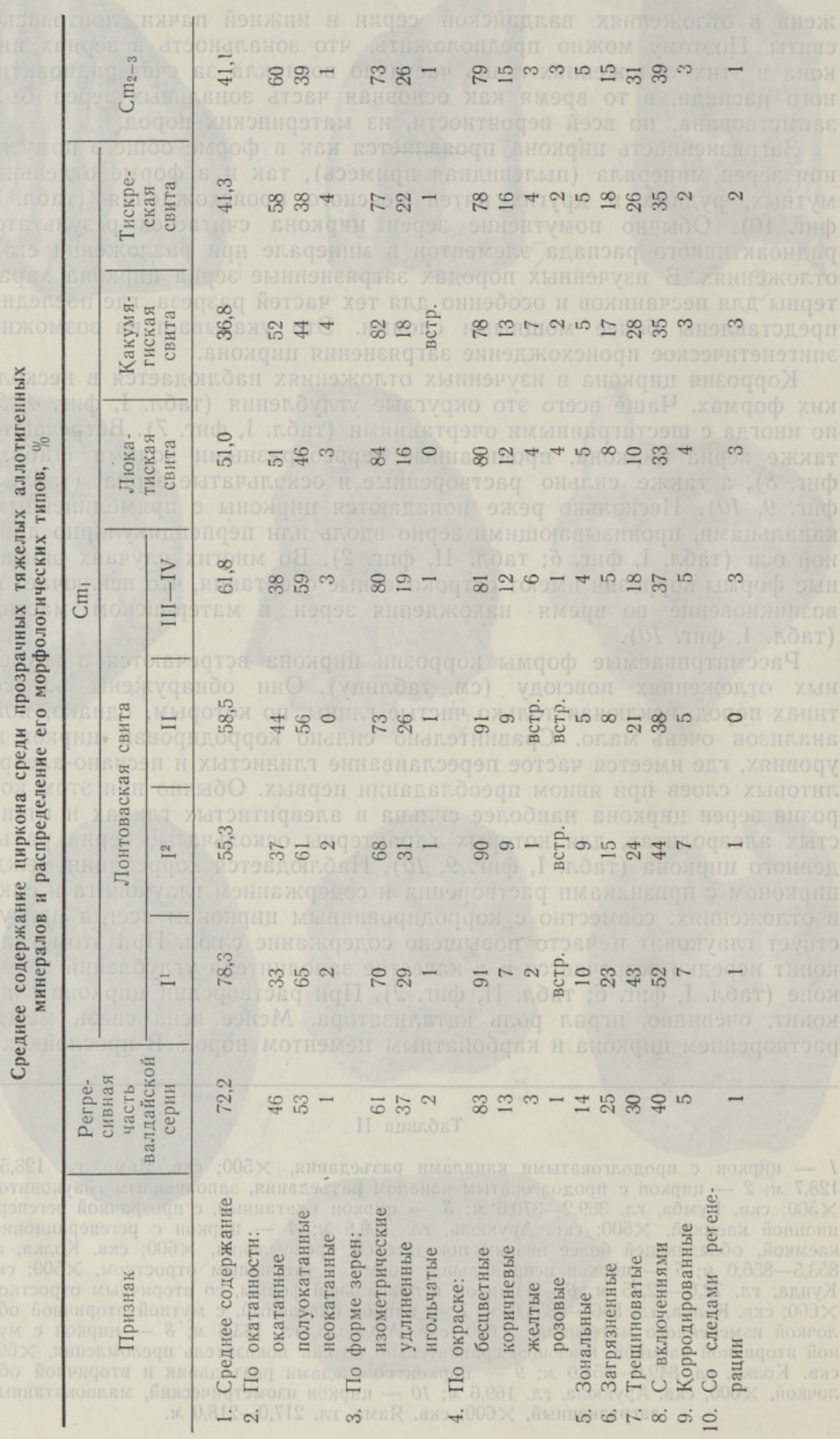


карбонатным цементом циркон обычно сильно корродирован, но такие же зерна циркона нередко встречаются и в частях разреза, где поблизости нет пород с карбонатным цементом.

Из форм регенерации циркона чаще встречается регенерационная каемка, имеющая максимальную толщину на вершинах пирамиды и сравнительно более узкую на гранях призмы (табл. II, фиг. 3,4). Более редки отдельные неправильные или пирамидальные наросты на зернах (табл. I, фиг. 9; табл. II, фиг. 5, 6). Вокруг некоторых прозрачных зерен наблюдаются и загрязненные неправильные вторичные окаймления цирконового состава, повторяющие форму окатанных зерен циркона (табл. II, фиг. 7). В глинистых отложениях подобные цирконовые окаймления всегда имеют сравнительно низкнй показатель преломления: $1,90-1,76$ (табл. II, фиг. 8).

Регенерированные зерна циркона обнаружены во всех типах пород, но чаще они приурочены к гравелитам, алевролитам и песчаникам, содержащим гальки. В глинистых отложениях вокруг зерен циркона найдены только мутные и неправильные каемки с низким показателем преломления, которые могли образоваться уже в материнских массивах, и, во всяком случае, их возникновение в постседиментационный период в данных отложениях остается под сомнением. В глинах, где встречаются цирконы с признаками регенерации, часто содержится вторичный каолинит.

Зачастую в пределах одного зерна циркона встречаются одновременно формы коррозии и регенерации, что указывает на тесную связь между ними (табл. I, фиг. 9; табл. II, фиг. 9).

Вторичные изменения циркона в основном изучались только в иммерсионных препаратах. Многие постседиментационные изменения (глауконитизация, хлоритизация и другие), широко развитые в кембрийских отложениях, еще мало изучены, и поэтому взаимосвязь между подобными явлениями нередко остается неясной, а природа и время их происхождения трудно определимыми. Основываясь на данных, полученных в результате изучения распределения и характера корродированных зерен циркона в отложениях, можно предположить, что коррозия циркона происходила здесь в ходе эпигенеза, особенно в его поздней стадин, под влиянием активных минерализованных межпластовых вод. Коррозии содействовали маломощные прослои пород с хорошими фильтрационными свойствами (песчаники, алевролиты) в глинах, обилие слюдистых и глинистых минералов, а также глауконит. Процессы регенерации циркона происходили также в стадии позднего эпигенеза, видимо, не без влияния активных минерализованных растворителей. По имеющимся предварительным данным, разъедание и регенерация циркона есть результат перераспределения материала в пределах одного зерна. Эти процессы происходили почти одновременно, хотя регенерация циркона началась, видимо, несколько позже, чем коррозия.

\section{ЛИТЕРАТ У Р А}

Агафонова Г. 1961. Некоторые морфологические особенности цирконов. Мин. сб. Львовск. геол. о-ва, № 15.

В ин челл А. Н., В и н челл Г. 1953. Оптическая минералогия, М.

Жиров K. К. 1952. О переходе циркона в метамиктное состояние. ДАН АН СССР, 85 , № 4.

К р асн о б а е в А. А. 1970. Зональность цирконов. Зап. Всес. мин. о-ва, ч. 99, вып. 4. Мардла А. К., Менс К. А., КалаЭ.А., Каяк К. Ф., Эрисалу Э. 1968. К стратиграфии кембрийских отложений Эстонии. В кн.: Стратиграфия нижнего палеозоя Прибалтики н коррелящия с другими районами. Вильнюс. 
Руденко С. А. 1968. Явления метамиктного распада минералов и его место в процессе минералообразования. Зап. Всес. мин. о-ва, ч. 97 , вып. 5.

$\mathrm{K}$ a ls beek T. 1967. Evolution of zirkons in sedimentary and metamorphic rocks. Sedimentology, 8, No. 2.

Marshall B. 1967. The present status of zirkon. Sedimentology, 9, No. 2.

Pacham G. H., Crook K. A. W. 1960. The principle cf diagenetic facies and some of its implication. J. Geol., 68, No. 4.

$\mathrm{S}$ axena S. K. 1966. Evolution of zirkons in sedimentary and metamorphic rocks. Sedimentology, 6, No. 1.

Ннститут геологии

Академии наук Эстонской ССР
Поступила в редакцию

$15 /$ XII 1971

\section{ANNE KLEESMENT}

\section{TSIRKOONI MORFOLOOGIA PÕHA-BALTIKUMI KAMBRIUMI SETETES}

Kambriumi läbilõige sisaldab savide, aleuroliitide ja liivakivide vahelduvaid kihte. Uuritavate kivimite raske fraktsiooni läbipaistvate allotigeensete mineraalide hulgas domineerib peaaegu eranditult tsirkoon, mis siin valdavalt esineb värvitute lühiprismaliste bipüramiidjate otstega teradena. Määrati tsirkooni morfoloogiliste erimite vahekorrad protsentides, mida on võimalik kasutada stratigraafiliste järelduste tegemisel. Küllaltki suurel hulgal tsirkooniteradel esineb korrosiooni- ja regeneratsioonitunnuseid, mida platvormilistes setetes on leitud harva. Tsirkooni korrosioon ja regeneratsioon on arvatavasti toimunud epigeneesi staadiumis, kusjuures korrosioon algas tōenäoliselt pisut varem kui regeneratsioon. Kõige intensiivsemalt on tsirkooni terad korrodeerunud savis esinevates õhukestes liivakivide ja aleuroliidi vahekihtides. Korrodeerunud tsirkooni puhul esineb glaukoniiti ning rohkesti savi- ja vilgumineraale.

\section{ANNE KLEESMENT}

\section{MORPHOLOGY OF ZIRCON IN THE CAMBRIAN DEPOSITS OF THE NORTHERN BALTIC}

The Cambrian profile is represented by an alternating complex of clays, silts and sandstones. Zircon plays almost exclusively a predominating part in the bulk of the transparent allotigenous heavy minerals of the sedimentary rocks studied. Here it is mainly represented by colourless short prism-shaped grains with bipyramidal ends. The relations of the morphological varieties of zircon were determined, which may be used for drawing stratigraphical conclusions. Quite a great number of zircon grains show symptoms of corrosion and regeneration, which are but seldom found in platform sediments. The corrosion and regeneration of zircon took probably place in the epigenetic stage, with corrosion phenomena having evidently started somewhat earlier than regeneration. The most intensively corroded zircon grains are distributed in the sandsone and silt interstratifications occurring in clays. The corrosion of zircon is accompanied by an abundance of clay and mica minerals as well as by an occurrence of glauconite. 